\title{
Phaeochromocytoma and acute cardiovascular death (with special reference to myocardial infarction)
}

\author{
C. D. COHEN \\ M.B.,Ch. B., M.R.C.P.(U.K.) \\ D. M. DENT \\ Ch.M., F.R.C.S.(Eng), F.C.S.(S.A.) \\ Departments of Medicine and Surgery, University of Cape Town Medical School and Groote Schuur Hospital, \\ Observatory, 7925, Cape, South Africa
}

\section{Summary}

The causes of death, as determined by autopsy, in 10 patients dying from the acute effects of phaeochromocytoma were myocardial infarction (five patients), left ventricular failure (two patients), cerebral haemorrhage (two patients) and circulatory collapse with malignant phaeochromocytoma (one patient). Most patients died shortly after admission during the course of a fulminant cardiovascular illness and the underlying tumour was unsuspected in eight instances. The clinical features and post-mortem cardiovascular findings are reviewed.

KEY WORDS: atheroma, left ventricular failure, cerebral haemorrhage, myocardial disease.

\section{Introduction}

When the clinical diagnosis of phaeochromocytoma is made, the patients have usually presented with characteristic paroxysmal or sustained hypertension and symptoms related to hypertension. In a significant proportion of cases, however, the lesion is only diagnosed at autopsy (Modlin et al., 1979; Sutton, Scheepo and Lie, 1981). Many of this latter group of patients have presented with an acute, severe cerebrovascular or myocardial illness. This mode of presentation forms a less well known but important clinical expression of this rare tumour. Myocardial disease in patients with phaeochromocytoma may take the form of left ventricular hypertrophy as a consequence of severe prolonged hypertension (Engelman, 1977; Van Way et al., 1974), as a catecholamine cardiomyopathy (Rose, 1974; Baker et al., 1972; Shapiro, Trethowan and Singh, 1982; Alpert et al., 1972), or, occasionally, as an acute myocardial infarction (Gupta, 1975; Priest, 1952; Boldt, Flexner and Ortner, 1957). The infarction may occur with or without demonstrable coro-

Reprint requests to Professor D. M. Dent. nary artery disease. This paper examines the clinical and pathological features of 10 patients who died an acute cardiovascular death and who harboured a phaeochromocytoma.

\section{Patients}

Examination of all clinical and autopsy records between 1961 and 1982 at Groote Schuur Hospital, Cape Town, revealed that there were altogether 34 patients in whom the diagnosis of phaeochromocytoma was made. Ten of these died an acute cardiovascular death, and form the basis of this article. The principal clinical features are presented in Table 1.

There were five males and five females and their mean age was 46 years. In the patients with preexisting symptoms, the mean duration was 21 months, the shortest history being of 1 day and the longest of 3 years. The primary presenting complaint (which in the majority of cases was new and of recent onset) was chest pain or dyspnoea in six patients and one each of epigastric pain, a 'flu-like' illness (with abdominal pain) and 'attacks' suggestive of catecholamine excess together with abdominal pain. The last patient had no cardiovascular symptoms and died of cardiovascular collapse during a laminectomy. Case 1 was known to have maturity onset diabetes and four additional patients had glycosuria recorded during the course of their illness. Cases 1 and 4 were known smokers; there was no record whether or not the remaining patients smoked.

Four of the six patients with chest pain and dyspnoea were found to be in left ventricular failure. Paroxysmal hypertension was recorded in four patients and sustained hypertension in three. Of interest was the fact that three patients of the group were normotensive. Retinopathy was recorded in half the cases. The electrocardiogram (ECG) showed left ventricular hypertrophy in four cases and evidence of myocardial infarction in three patients.

In eight patients, the attending clinicians did not 


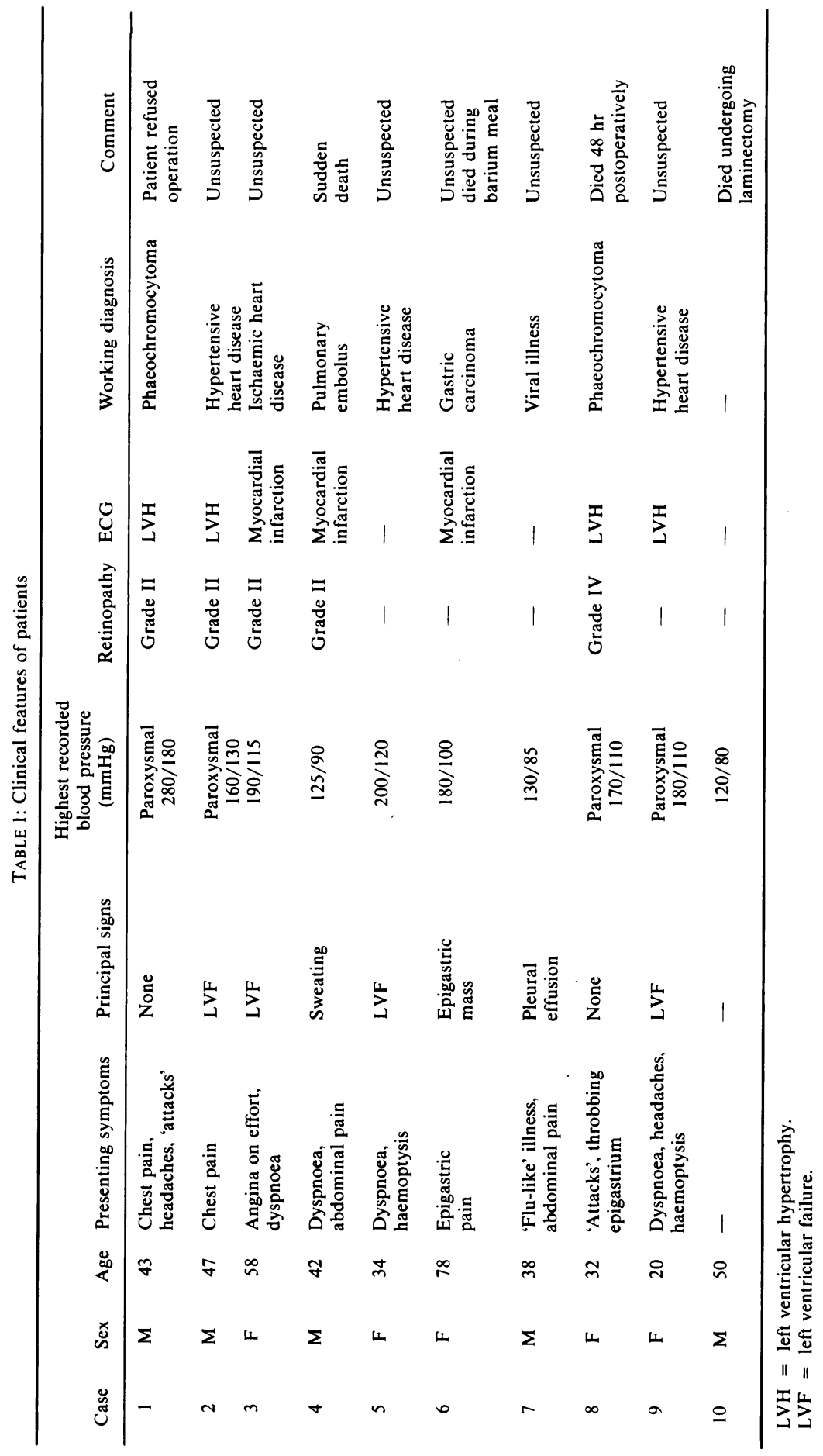


suspect that there was an underlying phaechromocytoma, their working diagnoses being shown in Table 1. In retrospect it is not difficult to reconcile the clinical features with an underlying phaeochromocytoma; examination of the notes, however, suggests that the attending clinicians' concentration was so focussed on the cardiovascular problem that the possibility of phaeochromocytoma did not come to mind. In the remaining two cases, an antemortem diagnosis of phaeochromocytoma was made: case 1 refused surgery, after extensive and conclusive investigation and case 8 died of pulmonary oedema $48 \mathrm{hr}$ after surgical removal of a phaeochromocytoma. These last two cases have been included as their mode of death was essentially similar to the undiagnosed cases.

All patients died during a short period of hospital admission in the course of a complicated and severe cardiovascular illness. In the unsuspected cases, a feature of the records was a failure ever to gain control of the clinical situation, whether it was cardiac failure, arrhythmia or hypertension. In retrospect this was hardly surprising as the medication was in all cases inappropriate and dangerous. Of the two patients where an antemortem diagnosis was made, case 1 was re-admitted comatose and died soon after, some 2 years after the diagnosis had been made and he had refused surgery, he having been managed on antihypertensive therapy. It is suspected that he was not drug compliant. The history of case 8 will be given in some detail.

The causes of death determined at autopsy are presented in Table 2; cerebral haemorrhage (two patients), myocardial infarction (five patients), left ventricular failure and ventricular fibrillation (two patients). The presence of an underlying phaeochromocytoma came as a surprise finding in eight of the 10 cases. The histology of the tumour in case 7 showed an undifferentiated neoplasm made up of tumour cells with large vesicular nuclei and abundant cytoplasm containing chromaffin granules consistent with the appearance of a phaeochromocytoma. There was no evidence of metastases or invasion. The patient died of circulatory collapse of undetermined cause. Four of the five patients dying from myocardial infarction had evidence of coronary artery disease. In case 8, a 32-year-old female, there was evidence of severe coronary atherosclerosis and in case 9, a 20-year-old female, who died from cerebral haemorrhage, the coronary vessels showed remarkably severe atheroma for a woman of that age.

\section{Case report}

A 32-year-old female was admitted with a 3-year history very suggestive of phaeochromocytoma: she had experienced attacks which consisted of throbbing headaches associated with pronounced sweating, nausea, flushing, rapid palpitations and a throbbing feeling in her epigastrium. The attacks would occur 3-4 times a day and lasted 5-10 min. She had been noted to be hypertensive after the birth of her child 3 years previously.

Examination revealed a paroxysmal blood pressure which varied between $210 / 120$ and $150 / 100 \mathrm{mmHg}$. She had Grade II hypertensive retinopathy and an apex beat in the 5th interspace outside the midclavicular line. Palpation of her epigastrium produced a typical attack on one occasion. The ECG showed left ventricular hypertrophy and non-specific ST and T wave flattening. The vanillyl mandelic acid (VMA) level was $118 \cdot 1 \mu \mathrm{mol} / 1$ (normal: $0-40$ ). Computerized axial tomography demonstrated a $6 \mathrm{~cm}$ mass in relation to the upper pole of the right kidney. She was prepared for operative removal of a suspected phaeochromocytoma with alpha blockade using phenoxybenzamine for 14 days. Two days before operation propranolol was added. The operation was uneventful and a $6 \mathrm{~cm}$ tumour was removed. All medication was stopped postoperatively.

Eighteen hours after surgery, she developed pulmonary oedema without evidence of fluid overload, and died despite resuscitative measures. At autopsy the myocardium showed foci of myocytolysis, stromal collapse and interstitial fibrosis. The aorta showed early fatty streaking. In addition there was $50 \%$ narrowing of the left anterior descending artery by atherosclerosis. Histology of the mass was that of a benign phaeochromocytoma.

\section{Discussion}

Phaeochromocytoma may be unsuspected during life and come as a surprise finding at autopsy. This was the case in eight of our 34 cases $(24 \%), 66 \%$ of a Mayo Clinic autopsy analysis (Sutton et al., 1981) and $35 \%$ of the Hammersmith/Newcastle/Belfast survey (Modlin et al., 1979). Retrospective examination of the clinical records of our cases revealed many features that could have been attributable to catecholamine excess, and yet the condition was never considered by the clinicians. In most of our cases the terminal illness was characterized by acute onset and inexorable progression. Egdahl and Chobanian (1966) have used the term 'acute' phaeochromocytoma and Weinberger (1963) has described the 'physiologically malignant' tumour, two descriptions that could easily be applied to our patients.

Catecholamine-induced myocarditis and congestive cardiac failure are well-recognized features of phaeochromocytoma (Engleman, 1977; Van Way et al., 1974). Less well documented, however, is the occurrence of myocardial infarction in patients with this tumour. We were able to find only nine cases 
TABLE 2. Pathology

\begin{tabular}{|c|c|c|c|c|c|c|}
\hline Case & Sex & Age & Aorta and large vessels & Heart & Coronary vessels & Cause of death \\
\hline 1 & $\mathbf{M}$ & 43 & Moderate atheroma & Normal & Normal & Cerebral haemorrhage \\
\hline 2 & $\mathbf{M}$ & 47 & Normal & $\begin{array}{l}\text { Recent infarction, } \\
\text { areas of focal ischaemia }\end{array}$ & $\begin{array}{l}\text { Extensive } \\
\text { occlusion } \\
\text { LAD*, RAD† } \\
\text { circumflex }\end{array}$ & Myocardial infarction \\
\hline 3 & $\mathbf{F}$ & 58 & Moderate atheroma & $\begin{array}{l}\text { Infarction of large } \\
\text { areas }\end{array}$ & $\begin{array}{l}\text { Extensive } \\
\text { atheroma LAD }\end{array}$ & Myocardial infarction \\
\hline 4 & $\mathbf{M}$ & 42 & Fatty streaking & Myocardial infarction & Normal & Myocardial infarction \\
\hline 5 & $\mathbf{F}$ & 34 & $\begin{array}{l}\text { Minor specks of } \\
\text { atheroma }\end{array}$ & Normal & Normal & $\begin{array}{l}\text { Left ventricular failure, } \\
\text { ventricular fibrillation }\end{array}$ \\
\hline 6 & $\mathrm{~F}$ & 78 & Atheroma & $\begin{array}{l}\text { Old and recent } \\
\text { infarction }\end{array}$ & Occlusion RAD & Myocardial infarction \\
\hline 7 & $\mathbf{M}$ & 38 & Normal & Normal & Normal & $\begin{array}{l}\text { Malignant phaeochromocytor } \\
\text { Mode of death unknown }\end{array}$ \\
\hline 8 & $\mathbf{F}$ & 32 & Normal & Myocardial degeneration & $\begin{array}{l}\text { Coronary } \\
\text { atherosclerosis } \\
40 \% \text { narrowing LAD }\end{array}$ & Left ventricular failure \\
\hline 9 & $\mathbf{F}$ & 20 & Early atheroma & Normal & $\begin{array}{l}\text { Severe atheroma } \\
\text { for age }\end{array}$ & Cerebral haemorrhage \\
\hline 10 & $\mathbf{M}$ & 50 & Normal & Myofibrillar degeneration & $\begin{array}{l}\text { LAD, RAD } \\
\text { occlusion }\end{array}$ & $\begin{array}{l}\text { Myocardial infarction while? } \\
\text { undergoing laminectomy 응 }\end{array}$ \\
\hline
\end{tabular}

reported in the literature (Table 3 ) and to these add five further cases.

TABLE 3. Patients with proven phaeochromocytoma and myocardial infarction (from the world literature)

\begin{tabular}{lcc}
\hline \multicolumn{1}{c}{ Reference } & Age (years) & Sex \\
\hline Bell et al., 1962 & 49 & $\mathrm{~F}$ \\
Boldt et al., 1957 & 56 & $\mathrm{~F}$ \\
Cushman, 1962 & 55 & $\mathrm{M}$ \\
Hotchkiss et al., 1967 & 70 & - \\
Huddle et al., 1982 & 70 & \\
Priest, 1952 & - & - \\
Rossi et al., 1968 & 22 & $\mathrm{M}$ \\
Wilkens et al., 1952 & 34 & $\mathrm{M}$ \\
\hline
\end{tabular}

Infarction has been described as painless in some patients (Boldt et al., 1957) and may occur with or without demonstrable coronary artery disease (Engelman, 1977). This analysis would support these contentions. Electrocardiographic evidence of myocardial ischaemia is not uncommon in phaeochromocytoma (Boldt et al., 1957) and this is most likely to be related to the presence of coronary artery atheroma. Six of our 10 patients had significant vessel disease. Van Vliet and his co-workers found signifi- cant atheroma and more than $25 \%$ coronary vesse narrowing in 14 out of 26 patients whose hearts were examined histologically (Van Vliet, Burchell an Titus, 1966). A striking observation in our series was the finding of inappropriate atheroma for age in tw $\vec{g}$ cases: a 20-year-old female (case 9) who died of $\frac{7}{2}$ cerebral haemorrhage had severe atheroma and a 32 year-old female (case 8) had greater than 50\% narrowing of the left anterior descending coronary artery. Platelet aggregation stimulated by increase $\bar{\Phi}$. catecholamines has been postulated as a pathophys? ological mechanism for severe irreversible postoperative pulmonary oedema (Sutton et al., 1981). Thiş however, was not demonstrated in our patient (case 8) who had both narrowing of the coronary vessels and a catecholamine cardiomyopathy. Conceivably both of these factors contributed to her sudde pulmonary oedema and death.

These findings raise several clinical issues. Firstly? phaeochromocytoma should be considered in alt patients presenting with an acute cardiovasculat illness, particularly when conventional therapy fails to achieve control. Secondly, as it appears that the disease is associated with severe atheroma anf్ cardiac disease and indeed may predispose to it, ane as the actuarial survival for those patients who haveo had successful surgical resection is the same as fo $\bar{P}$ 
normal people (Remine et al., 1974), we urge that early diagnosis and treatment may prevent the cardiac morbidity and mortality.

Finally, the use of beta-blocking agents in patients with phaeochromocytoma should be carefully considered in the light of these findings. On the one hand, there is a persuasive argument for their use. Catecholamines are known to cause myocardial necrosis and focal myofibrillar degeneration and this is one hypothesis for the evolution of congestive cardiomyopathy (Van Vliet et al., 1966; Rose, 1974). It is also possible that they may also stimulate the formation of atheroma. As the occurrence of myocardial infarction may be due to the effects of sudden beta stimulation on the heart and as beta blockade has been shown to decrease the incidence of sudden deaths due to myocardial infarction (Lubbe, 1978; Multicentre International Study, 1975; Opie, 1980), there is an attractive argument to use these agents in patients with phaeochromocytoma. On the other hand, beta blockade in this situation is not entirely without potential problems of a serious nature. Because of the negative inotropic effect of beta blockers, extreme caution it recommended in their use when congestive cardiac failure and myocarditis are present; they should only be given once adequate alpha blockade is established.

\section{References}

AlPert, L., Pai, S.J., Zak, F.F. \& Werthamer, S. (1972) Cardiomyopathy associated with a phaeochromocytoma. Archives of Pathology, 93, 544.

BAKer, G., ZeTler, N., Wertzner, S., LeACH, J. \& AlbuQuerque, N.M. (1972) Phaeochromocytoma without hypertension presenting as cardiomyopathy. American Heart Journal, 83, 688.

Bell, M., BLAKEMORE, W. \& Rose, E. (1962) Some vagaries of phaeochromocytoma. Four illustrative cases. Annals of Internal Medicine, 57, 406 .

Boldt, M., Flexner, M. \& Ortner, A. (1957) Phaeochromocytoma associated with painless myocardial infarction. Annals of Internal Medicine, 46, 1165.

Cushman, P. (1962) Familial endocrine tumours. American Journal of Medicine, 32, 352.

EgDaHL, R.H. \& Chobanian, A.V. (1966) Acute phaeochromocytoma. Surgical Clinics of North America, 46, 645.
Engelman, K. (1977) Phaeochromocytoma. Clinical Endocrinology and Metabolism, 6, 769.

Gupta, K. (1975) Phaeochromocytoma and myocardial infarction. Lancet, i, 281.

Hotchiss, R., Davidson, A., Messina, E. \& Redisch, W. (1967) Phaeochromocytoma. Analysis of cardiovascular symptomatology, preoperative diagnostic procedure, surgical approach and the genetic aspect and report of 5 cases. Annals of surgery, 6, 1021. Huddle, K.R.L., Bisceglie, D.A. \& Feldman, C. (1982) Phaeochromocytoma case reports. South African Medical Journal, 61, 286.

LUBBE, W.F. (1978) Clinical usefulness of the beta antagonists-Review article. South African Medical Journal, 54, 139.

Modlin, I.M., FARndon, J.R., SHEPHERd, A., Johnston, I.D.A., KENNEDY, T.L., MONTGOMERY, D.A.D. \& Welboun, R.B. (1979) Phaeochromocytoma in 72 patients: clinical and diagnostic features, treatment and longterm results. British Journal of Surgery, 66, 456.

MULTICENTRE INTERNATIONAL STUDY (1975) Improvement in prognosis of myocardial infarction by long term beta adrenoceptor blockade using practolol. British Medical Journal, 3, 721.

OPIE, L.H. (1980) Drugs and the heart. Lancet i, 693.

Priest, W.M. (1952) Phaeochromocytoma with fatal myocardial infarction in a man aged 22. British Medical Journal, 2, 860.

Remine, W., Chong, G.C., Van Heerden, J.A., Sheldon, G., SHePS, M.D., Edgar, G. \& HARRISON, J.R. (1974) Current management of phaeochromocytoma. Annals of Surgery, 179, 740.

RoSE, A.G. (1974) Catecholamine induced myocardial damage associated with phaeochromocytoma and tetanus. South African Medical Journal, 48, 1285.

Rossim P., Young, I.S. \& PANKe, W. (1968) Techniques, usefulness and hazards of arteriography of phaeochromocytoma. Review of 99 cases. Journal of the American Medical Association, 205, 547.

ShaPIRO, L.M., TreThowaN, N. \& Singh, S.P. (1982) Normotensive cardiomyopathy and malignant hypertension in phaeochromocytoma. Postgraduate Medical Journal, 58, 110.

SutTon, M.G., SCheepo, S.G. \& LiE, J.T. (1981) Prevalence of clinically unsuspected phaeochromocytoma-review of a 50 year autopsy series. Mayo Clinic Proceedings, 56, 354.

Van Vliet, P., Burchell, H.B. \& Titus, J.L. (1966) Focal myocarditis associated with phaeochromocytoma. New England Journal of Medicine, 274, 1102.

Van Way, C., Scott, H.W., Page, D. \& Rhamy, R. (1974) Phaeochromocytoma. Current Problems in Surgery. June.

Weinberger, M.A. (1963) Phaeochromocytoma. Archives of International Medicine, 112, 677.

Wilkens, R.M., Greer, W.E.R., Culbertson, J.W., Halperin, M.H., LITTER, J., BURNETT, C.H. \& SMITHWICK, R.H. (1952) Extensive laboratory studies of a patient with phaeochromocytoma before and after successful operation (1950). Archives of International Medicine, 86, 51.

(Accepted 29 June 1983) 